\title{
MORPHOLOGICAL AND BIOCHEMICAL PARAMETERS IN Wistar RATS INFLUENCED BY MOLYBDENUM AND ITS OXIDE NANOPARTICLES
}

\section{E.A. SIZOVA', 2, S.A. MIROSHNIKOV1, V.V. KALASHNIKOV 3}

\author{
${ }^{1}$ All-Russian Research Institute of Beef Cattle Breeding, Federal Agency of Scientific Organizations, 29, ul. 9 Yan- \\ varya, Orenburg, 460000 Russia, e-mail sizova-178@ya.ru, vniims.or@mail.ru; \\ ${ }^{2}$ Orenburg State University, 13, prosp. Pobedy, Orenburg, 460018 Russia; \\ ${ }^{3}$ All-Russian Research Institute of Horse Breeding, Federal Agency of Scientific Organizations, pos. Divovo, \\ Rybnovskii Region, Ryazan Province, 391105 Russia \\ (ORCID: Sizova E.A. orcid.org/0000-0002-5125-5981) \\ Acknowledgements: \\ Studies were performed using standard techniques in the Laboratory of Agroecology of Nanomaterials and Test \\ Center of All-Russian Research Institute of Beef Cattle Breeding (accreditation certificate RA. RU.21PF59 from \\ 12/02/15). Analysis of chemical elements was performed in the laboratory of ANO Center for Biotic Medicine, Moscow \\ (accreditation certificate GSEN.RU.TSAO.311, registration number in the State Register ROSS RU. 0001.513118) \\ Supported by Russian Science Foundation (project № 14-36-00023) \\ Received July 11, 2016
}

\section{Abstract}

Despite widespread use of nanoparticles in industry and medicine, there is very little information about how the newly developed nanomaterials interact with biological objects. Certain properties of the Mo-containing nanoparticles (NPs) suggest their possible toxic effect on warmblooded animals. In this paper we compared the effect of Mo NPs (at 1 and $25 \mathrm{mg} / \mathrm{kg}$ ) and its oxide MoO3 NPs (at 1.2 and $29 \mathrm{mg} / \mathrm{kg}$ ), when administrated parenterally, on metabolic parameters and the exchange of chemical elements in Wistar laboratory rats. There, we assessed the red and white blood cell counts, the hemoglobin level, the activity of catalase (CAT) and superoxide dismutase (SOD) (for oxidative status), the ALT, AST, LDH, GGT, creatine kinase activity, blood creatinine, bilirubin and urea concentrations (for metabolic status) at days 1, 7 and 14. A day after Mo NPs and $\mathrm{MoO}_{3}$ NPs administration the number of blood leukocyte lowered by $11.3 \%(\mathrm{P}<0.05)$ and $58.5 \%(\mathrm{P}<0.01)$, respectively. Also, a decrease in monocyte number by $18.9(\mathrm{P}<0.05)$, $41.9(\mathrm{P}<0.01), 51.7(\mathrm{P}<0.05)$ and $83.3 \%(\mathrm{P}<0.001)$ as depending on NPs chemical composition and doses was characteristic, though on day 14 a significant difference to control $(54.5 \%, \mathrm{P}<0.05)$ was found only for $\mathrm{MoO}_{3} \mathrm{NPs}$ at a dose of $29 \mathrm{mg} / \mathrm{kg}$. The number of thrombocytes was the highest on day 14 for the maximum dosage of both NPs leading to hindered blood microcirculation. The experiments also showed an increase in serum aminotransferases, GGT and LDH activity. In sum, we observed manifestations of oxidative stress, anemia and capillary-trophic insufficiency in the animals administrated with high doses of molybdenum and Mo oxide NPs. These signs were progressing and the most apparent for molybdenum oxide NPs. Given the comparable doses used, the molybdenum nanoparticles exhibit lower toxicity as compared to its oxide.

Keywords: catalase, superoxide dismutase, glutamyl transferase, lactate dehydrogenase, aminotransferase, nanoparticles of molybdenum, nanoparticles of molybdenum trioxide

Molybdenum nanoforms are widely used in modern technologies [1, 2], e.g. for multifunctional electrocalalysis [3] and production of lubricants [4]. Apart from that, ultradisperse products containing molybdenum and its compounds show unique biological properties, which allows using them for oncotherapy [5], as antibiotics [6, 7] and antifungal agents [8], and for blue-green algae growth promotion [9].

Molybdenum is a well-studied essential microelement. Its participation in enzymatic systems is well-known [10]. Ranges of molybdenum deficiency, sufficiency and toxicity have been described [11]. Background [12], threshold and toxic concentration of molybdenum for invertebrates in soils have been reported [13]. However, the knowledge on consequences of interaction of newly developed molybdenum-based nanomaterials with biological objects is still ex- 
tremely poor. At the same time, according to investigative studies, biological effects of nanoforms of molybdenum are much more expressed. Various models have been used to demonstrate this. For example, entry of molybdenum oxide nanoparticles into soil leads to high mortality rate, adaptive changes of antioxidant enzyme activity and inhibition of $\mathrm{Cr}, \mathrm{Fe}, \mathrm{Mg}, \mathrm{Mn}, \mathrm{Ni}, \mathrm{Si}, \mathrm{V}$ metabolism in Eisenia fetida [14]. The presence of molybdenum nanoparticles in water has a negative impact on cell membrane permeability in Stylonychia mytilus and leads to processes, accompanying the damage. Analysis of collected data on biological effects of molybdenum-based nanoparticles suggests that they may have a toxic effect on warm-blooded animals.

Here we for the first time compared the biological effects of molybdenum nanoparticles and molybdenum oxide on rats, the homeothermic mammals.

The objective of this work was the examination of morphological and biochemical blood parameters, morphological and functional characteristics of tissue and chemical element metabolism in model objects due to the effects of molybdenum nanoparticles and molybdenum oxide.

Technique. Molybdenum and molybdenum oxide nanoparticles (NPs) (Mo NPs and $\mathrm{MoO}_{3}$ NPs) were obtained by plasma chemical synthesis (OOO Platina, Moscow). Mo NPs products $\left(\mathrm{d}=50 \mathrm{~nm}\right.$, specific surface area $14 \mathrm{~m}^{2} / \mathrm{g}$, Z-potential $\mathbf{- 4 3} \pm 0,52 \mathrm{mV}$ ) contained $99,7 \%$ Mo and $0,3 \% \mathrm{O}_{2}$, and $\mathrm{MoO}_{3}$ NPs $\left(\mathrm{d}=92 \mathrm{~nm}\right.$, specific surface area $12 \mathrm{M}^{2} / \Gamma$, Z-potential $\left.-43 \pm 0,21 \mathrm{mV}\right)$ contained $99,8 \%$ Mo and $0,2 \% \mathrm{O}_{2}$. The material attestation (determination of particle size, polydispersity, voluminosity, fraction content, surface area) included electronic scanning, transmission and atomic force microscopy using LEX T OLS4100, JSM 7401F и JEM-2000FX (JEOL, Japan). Particle size distribution was examined using a Photocor Compact analyzer (OOO Photocor, Russia). Nanoparticle samples were dispersed in saline solution using UZDN-2T (NPP Akadempribor, Russia) (35 kHz, $300 \mathrm{~W}, 10 \mathrm{uA}, 30 \mathrm{~min})$.

The studies were performed in 75 Wistar white male rats, with the weight of 150-180 $\mathrm{g}$ in standard vivarium conditions (experimental biological clinic, Orenburg State University). The diet of animals (State Standard GOST R 5025892) complied with the requirements of the Good Laboratory Practice in conducting preclinical research in the Russian Federation (State Standard GOST 51000.4-96). The experiments were performed in accordance with the provisions of the Geneva Convention and the principles of Good Laboratory Practice (National Standard of the Russian Federation GOST R 53434-2009), as well as recommendations set out in The Guide for the Care and Use of Laboratory Animals (National Academy Press Washington, DC 1996). After the preliminary period ( 1 month) the animals were divided into 5 groups $(n=15$ per group). Mo NPs were administered intraperitoneally in a single dose of 1 and 25 $\mathrm{mg} / \mathrm{kg}$ of live weight in groups I and II, respectively, and in groups III and IV $\mathrm{MoO}_{3}$ NPs were administered at the dose of 1.2 and $29 \mathrm{mg} / \mathrm{kg}$, respectively. Saline solution was injected to control animals.

Biomaterial for the study was obtained after decapitation of rats under Nembutal anesthesia ( 5 species for each option of the experiment and control in 1,7 , and 14 days after administration of nanopreparations). Blood for examination of morphological parameters was placed in vacuum tubes with anticoagulant, for biochemical studies - into vacuum tubes with a coagulation activator (thrombin). Morphological blood composition and hemoglobin concentration were estimated using an nautomatic hematological analyzer URIT-2900 Vet Plus (URIT Medical Electronic Group Co., Ltd, China). The biochemical blood serum test was performed using an automatic biochemical analyzer CS-T240 (DIRUI Industrial Co., Ltd, China) and commercial veterinary kits (DiaVetTest 
by DIAKON-DS, Russia; Randox Laboratories Ltd., Great Britain). The content of chemical elements in the examined samples studied was measured using a mass spectrometer Elan 9000 and an atomic emission spectrometer Optima 2000V (Perkin Elmer, USA). The samples were ashed using microwave decomposition system Multiwave-3000 (Anton Paar, Austria).

For liver microstructure studies, samples were fixed in $10 \%$ neutral formalin and embedded in paraffin mixture HISTOMIX ${ }^{\circledR}$ (OOO BioVitrum, Russia). 5-6 $\mu \mathrm{m}$ thick histological sections were prepared using a semi-automatic microtome (01 MW, Tekhnom, Russia), stained with Mayer's Haematoxylin and Eosin and examined under a light microscope MT 5300L (Meiji Techno Co., Ltd, Japan, $\times 400)$.

The data are presented as the arithmetic mean $(M)$ with the standard error of the mean $(m)$. Statistical analysis was performed using ANOVA (Statistica 10.0 software package, StatSoft Inc., USA) and Microsoft Excel. The validity of differences in the indicators compared was determined by Student's $t$ - test. The values were considered statistically significant at $\mathrm{P}<0.05$.

Results. Significant morphological changes of blood were observed as early as 1 day after administration of molybdenum and molybdenum oxide nanoparticles (Table 1). For example, leukocyte counts in groups II and IV have decreased by $11.3 \%(\mathrm{P}<0.05)$ and $58.5 \%(\mathrm{P}<0.01)$.

1. Morphological blood parameters in Wistar rats upon intraperitoneal administration of $\mathrm{Mo}$ and $\mathrm{MoO}_{3} \mathrm{NPs}$ at various doses $(M \pm m, n=75)$

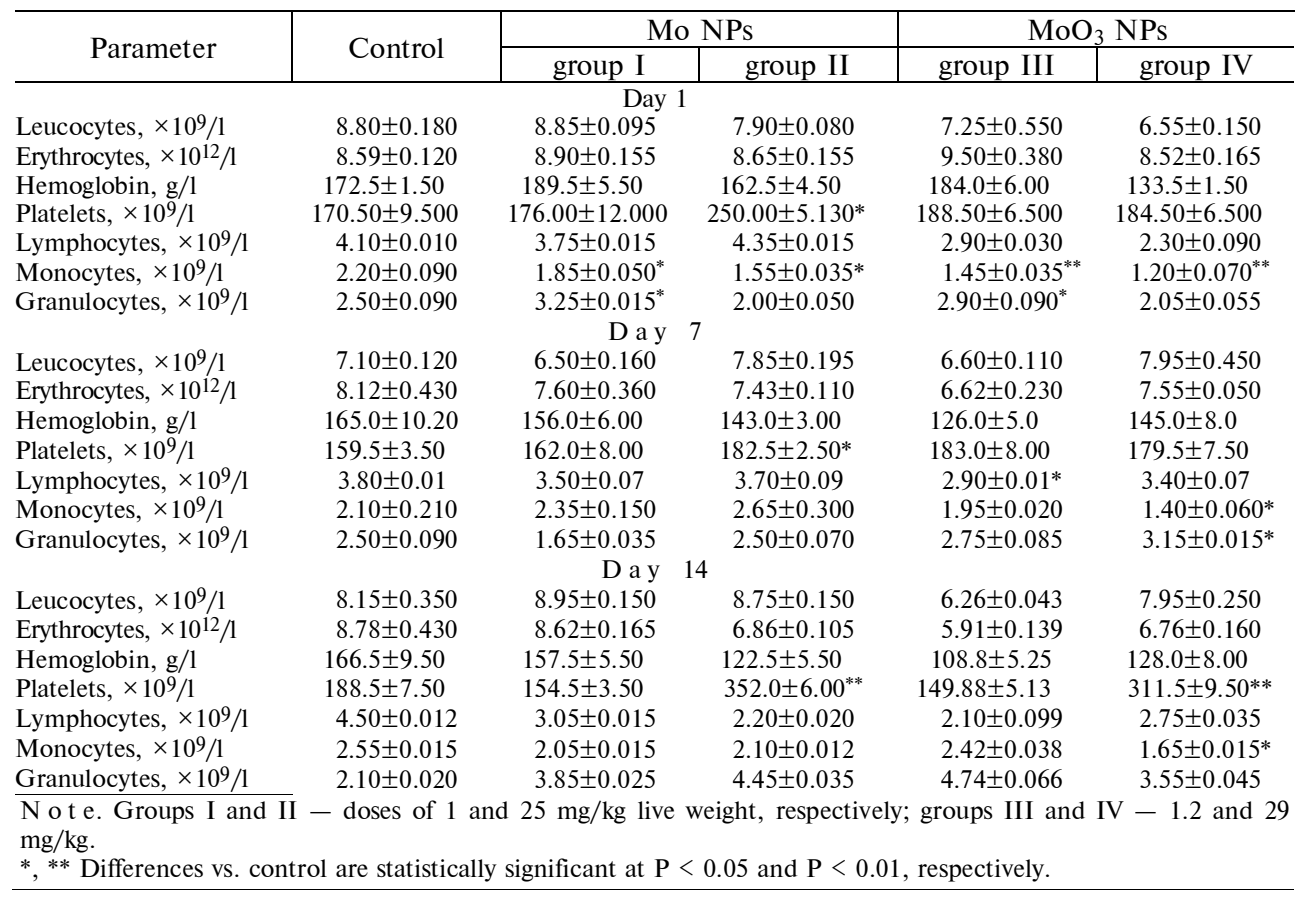

The effect of molybdenum-based nanoparticles was characterized by decrease in monocyte counts on day 1 by $18.9(\mathrm{P}<0.05), 41.9(\mathrm{P}<0.01), 51.7$ $(\mathrm{P}<0.05)$ and $83.3 \%(\mathrm{P}<0.001)$ in groups I, II, III and IV, respectively. In 7 days this difference amounted to $55.6(\mathrm{P}<0.05), 27.3(\mathrm{P}<0.05), 7.7$ and $50.0 \%(\mathrm{P}<0.05)$. At the time of completion of the experiment significant differences were only observed between the control and group IV $(54.5 \%, \mathrm{P}<0.05)$. The nanoparticle effects with regard to the monocytes observed by us differed dramatically from those reported for polystyrene nanoparticles [16] and $\mathrm{Cu}$ and $\mathrm{Fe}$ nanoforms [17]. Similar dynamics was observed for lymphocytes, the number 
more severe in the course of time (Table 2). For example, with regard to ALT and total bilirubin, the difference as compared to control amounted to 18.2$62.0 \%$ on day $1,119.0 \%$ on day 7 , and $272.0 \%$ on day 14 . The difference was even more significant for AST, i.e. 222.0-352,0\%; with regard to bilirubin, significant (4.8-fold) increase was observed for $\mathrm{MoO}_{3}$ NPs as early as on day 1 . Significant $(\mathrm{P}<0.05)$ decrease in ALT activity was observed for maximum dose of $\mathrm{MoO}_{3}$ NPs $(29 \mathrm{mg} / \mathrm{kg})$ on day 1 . This can be indicative of glomerular filtration impairment, which is confirmed by high values for creatinine (14.3-fold difference with the control, $\mathrm{P}<0.01)$ and urea $(30.8 \%$ higher, $\mathrm{P}<0.01)$.

We did not detect an increase in serum $\gamma$-glutamyl transferase (GGT) and lactate dehydrogenase (LDH) activity. The values close to upper limit of normal were detected on day 1 for minimum doses of Mo NPs and $\mathrm{MoO}_{3} \mathrm{NPs}$, as well as on day 7 and 14 at the minimum doses of both nanoparticles. Such dynamics of GGT and LDH activity may be indicative of membrane destruction in a small part of cell population and weak microsomal oxidation induction due to nanoparticles of transition metals [22]. At the same time, with increase in duration of impact up to 14 days at the minimum dose of Mo NPs GGT activity increased 5-fold, which may be considered as a sign of oxidative stress due to effect of Mo NPs. This phenomenon was previously reported for mouse fibroblasts (line L929) when generation of active oxygen forms with subsequent decrease in glutathione content and catalase activity [23]. LDH activity only increased at high doses of the agent (mostly $\mathrm{MoO}_{3}$ NPs), which may be considered as moderately toxic, as compared to other transition metals [24].

The development of oxidative stress was also confirmed by the dynamics of catalase (CT) and superoxide dismutase (SOD) activity. The peak values for CT were recorded at the high dose of $\mathrm{MoO}_{3}$ NPs $(29 \mathrm{mg} / \mathrm{kg})$ on day 7 and day 14, with 9.0-fold $(\mathrm{P}<0.01)$ and 7.9 -fold $(\mathrm{P}<0.05)$ difference, respectively, compared to control. Minimum doses on day 1 caused a rapid increase in catalase activity (4.1-fold compared to control); on day 7 the values decreased to 1.5 -fold difference, and by day 14 increased again, but not up to the initial level. Presumably, catalase activation takes place in response to increase in lipid peroxidation and accumulation of hydrogen peroxide and other oxidative stress products, as catalase metabolizes them and prevents their accumulation in cells. However, according to some researchers, Mo NPs are not toxic and can act as antioxidants, e.g. by showing protective effect in contact with peroxide compounds $\left(\mathrm{H}_{2} \mathrm{O}_{2}\right)$ and $\mathrm{ZnO}-\mathrm{NPS}$, which has been demonstrated for cell lines of human mammary gland adenocarcinoma (MCF-7) and fibrosarcoma (HT-1080). Mo NPs have been reported to significantly increase glutathione content in MCF-7 line (1.6-fold) and HT-1080 line (1.3-fold), which could be compared to the effect of antioxidant drug N-acetylcysteine (NAC) [25].

Both minimum microstructural changes (granular degeneration, hepatocyte hypertrophy and hyperchromia of their nucleus) in case of low doses of Mo NPs and $\mathrm{MoO}_{3} \mathrm{NPs}$, and significant pathological changes (large areas of hepatosis and necrosis) in case of high doses of $\mathrm{MoO}_{3}$ NPs were observed in liver.

Antagonistic interactions of molybdenum with other microelements could contribute to effect of molybdenum nanoparticles in animals [26]. Analysis of liver composition, muscle tissues and brain of animals for 25 chemical elements has revealed significant changes related to three of them, i.e. Mo, Fe and Ca. Thus, in liver in groups I and II a decrease in Fe content by $31.1(\mathrm{P}<0.01)$ and $38.9 \%(\mathrm{P}<0,001)$ was observed on day 1 , and by $24.0(\mathrm{P}<0.01)$ and $76.1 \%(\mathrm{P}<0.001)$ on day 7 , respectively. The difference for brain tissues amounted to $48.3(\mathrm{P}<0.001)$ and $90.1(\mathrm{P}<0.001)$, and $21.1(\mathrm{P}<0.01)$ and 
$41.5 \%(\mathrm{P}<0,001)$, respectively. Application of $\mathrm{MoO}_{3} \mathrm{NPs}$ was accompanied by similar changes. With regard to $\mathrm{Ca}$, significant increase in accumulation in liver was only observed on day 1 , by $17.1 \%(\mathrm{P}<0.05)$ in group I and by $26.3 \%(\mathrm{P}<0.01)$ in group II. Mo level analysis has demonstrated the same dynamics (Fig.). Peak values were observed on day 1 and were directly dependent on Mo administration dose with clinical difference (136.9\%) for liver. During the next 7 days the amount of Mo in liver decreased in animals of group II by $41.55 \%$, of group I - by $4.41 \%$, as compared to the value on day 1 .

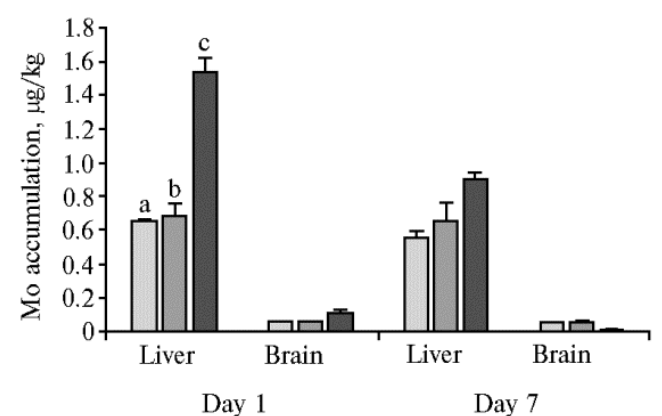

Mo accumulation in organs of Wistar rats upon single administration of Mo nanoparticles at various doses: $\mathrm{a}-$ control, $\mathrm{b}-1 \mathrm{mg} / \mathrm{kg}, \mathrm{c}-25 \mathrm{mg} / \mathrm{kg}$.

Accumulation in brain at a dose of $1 \mathrm{mg} / \mathrm{kg}$ was comparable with that of intact animals. Increase of the dose up to $25 \mathrm{mg} / \mathrm{kg}$ led to an increase in Mo content by $83.3 \%$ on day 1 and its decrease on day 7 up to the values below control ones.

The obtained results are generally expectable. It is known that molybdenum is one of the essential microelements and its deficiency is accompanied by development of a number of pathologies in humans and animals [27]. However, reports exist on toxic effect of molybdenum in the body, a strong connection between excessive Mo content and development of asthma [28], alveolar and bronchial adenomas and carcinomas [29], etc.

So, administration of Mo nanoparticles in rats is accompanied by capillary-trophic insufficiency, signs of oxidative stress, with more clear manifestation in case of molybdenum oxide nanoparticles. Considering the comparable doses of the agents, we may suggest that Mo nanoparticles are less toxic than nanoforms of its oxide.

\section{REFEREN C ES}

1. Chen Y.X., Wu C.W., Kuo T.Y., Chang Y.L., Jen M.H., Che n I.W. Large-scale production of large-size atomically thin semiconducting molybdenum dichalcogenide sheets in water and its application for supercapacitor. Sci. Rep., 2016, 26(6): 26660 (doi: 10.1038/srep26660).

2. Naylor C.H., Kybert N.J., S chneier C., Xi J., Rom e ro G., S aven J.G., Liu R., J o h n s o n A.T. Scalable production of molybdenum disulfide based biosensors. ACS Nano, 2016, 10(6): 6173-6179 (doi: 10.1021/acsnano.6b02137).

3. Tadi K.K., Palve A.M., Pal S., Sud e e p P.M., N a ra y a n a T.N. Single step, bulk synthesis of engineered $\mathrm{MoS}_{2}$ quantum dots for multifunctional electrocatalysis. Nanotechnology, 2016, 27(27): 275402 (doi: 10.1088/0957-4484/27/27/275402).

4. Parenago O.P., Bakunin V.N., Kuz'mina G.N., Suslov A.L., Vedeneev a L.M. DAN, 2002, 383(1): 84-86 (in Russ.).

5. Liu Q., Sun C., He Q., Liu D., Khalil A., Xiang T., Wu Z., Wang J., Song L. Ultrathin carbon layer coated $\mathrm{MoO}_{2}$ nanoparticles for high-performance near-infrared photothermal cancer therapy. Chem. Commun. (Camb.), 2015, 51(49): 10054-10057 (doi: 10.1039/c5cc02016f).

6. F a k h ri A., N e ja d P.A. Antimicrobial, antioxidant and cytotoxic effect of Molybdenum trioxide nanoparticles and application of this for degradation of ketamine under different light illumination. J. Photochem. Photobiol. B, 2016, 159: 211-217 (doi: 10.1016/j.jphotobiol.2016.04.002).

7. Zhang W., Shi S., Wang Y., Yu S., Zhu W., Zhang X., Zhang D., Yang B., Wang X., Wang J. Versatile molybdenum disulfide based antibacterial composites for in vitro enhanced sterilization and in vivo focal infection therapy. Nanoscale, 2016, 8(22): 1164211648 (doi: 10.1039/c6nr01243d).

8. Qureshi N., Chaudhari R., Mane P., Shinde M., Jadakar S., Rane S., $\mathrm{Kale}$ B., B hale rao A., A malnerkar D. Nanoscale Mo- $\mathrm{MoO}_{3}$ entrapped in engineering thermoplastic: inorganic pathway to bactericidal and fungicidal action. IEEE Transactions on NanoBioscience, 2016, 15(3): 258-264 (doi: 10.1109/TNB.2016.2535285). 
9. Sam J.S., Yuvakkumar R., Suriya P.R., Karunakaran G., Rajendran V., Ho ng S.I. Facile and novel synthetic method to prepare nano molybdenum and its catalytic activity. IET Nanobiotechnology, 2015, 9(4): 201-208 (doi: 10.1049/iet-nbt.2014.0015).

10. Me ndel R.R., B it t ne r F. Cell biology of molybdenum. BBA, 2006, 1763: 621-635 (doi: 10.1016/j.bbamcr.2006.03.013).

11. McBride M.B., Richards B.K., Stee nhuis T., Spiers G. Molybdenum uptake by forage crops grown on sewage sludge-amended soils in the field and greenhouse. J. Environ. Qual., 2000, 29: 848-854.

12. H e Z.L.L., Y a ng X.E., S t offe 11 a P.J. Trace elements in agroecosystems and impacts on the environment. J. Trace Elem. Med. Bio., 2005, 19: 125-140 (doi: 10.1016/j.jtemb.2005.02.010).

13. Van G estel C.A.M., B org man E., Verweij R.A., Di e z-O rtiz M. The influence of soil properties on the toxicity of molybdenum to three species of soil invertebrates. Ecotox. Environ. Safe., 2011, 74: 1-9 (doi: 10.1016/j.ecoenv.2010.10.001).

14. Lebedev S., Yausheva E., Galaktionova L., S izova E. Impact of molybdenum nanoparticles on survival, activity of enzymes, and chemical elements in Eisenia fetida using test on artificial substrata. Environ. Sci. Pollut. Res. Int., 2016, 23(18): 18099-18110.

15. Kosyan D., Rusakova E., Sizova E., Mi roshnikov S., Skalni y A. Impact of nanoparticles of heavy metals and their oxides on Stylonychia mytilus. Ecology, Environment and Conservation, 2015, 21: 113-119.

16. Fernández-Urrusuno R., Fattal E., Rodrigues J.M., Féger J., Bedossa P., Couvreur P. Effect of polymeric nanoparticle administration on the clearance activity of the mononuclear phagocyte system in mice. J. Biomed. Mater. Res., 1996, 31(3): 401-408.

17. Yausheva E.V., M i roshnikov S.A., Kvan O.V. Vestnik Orenburgskogo gosudarstvennogo universiteta, 2013, 12(161): 203-207 (in Russ.).

18. Ott H.C., Prior C., He rold M., Riha M., Laufer G., Ott G. Respiratory symptoms and bronchoalveolar lavage abnormalities in molybdenum exposed workers. Wien Klin Wochenschr., 2004, 116(1): 25-30.

19. Khanturina G.R., I b r a eva L.K., Le bedeva E.A. Uspekhi sovremennogo estestvoznaniya, 2012, 12: 11-13 (in Russ.).

20. Ostroushko A.A., Danilova I.G., Medvedeva S.Yu., Gette I.F., Tonk u shi n a M.O. Ural'skii meditsinskii zhurnal, 2010, 9(74): 114-117 (in Russ.).

21. Ostroushko A.A., Get te I.F., Danilova I.G., Medvedeva S.Yu., Ton kushina M.O., Prokof'eva A.V. Ural'skii meditsinskii zhurnal, 2011, 11(89): 75-79 (in Russ.).

22. Asadi F., Mohseni M., Dadashi Noshahr K., Soley mani F.H., Jalilvand A., $\mathrm{He}$ id a ri A. Effect of Molybdenum nanoparticles on blood cells, liver enzymes, and sexual hormones in male rats. Biol. Trace Elem. Res., 2016: 1-7 (doi: 10.1007/s12011-016-0765-5).

23. Siddiqui M.A., Saquib Q., Ahamed M., F arshori N.N., Ahm ad J., Wahab R., Khan S.T., A 1 hadlaq H.A., Musarrat J., Al-Khedhairy A.A., Pant A.B. Molybdenum nanoparticles-induced cytotoxicity, oxidative stress, $\mathrm{G}_{2} / \mathrm{M}$ arrest, and DNA damage in mouse skin fibroblast cells (L929). Colloids and Surfaces B: Biointerfaces, 2015, 1(125): 73-81 (doi: 10.1016/j.colsurfb.2014.11.014).

24. Hus s a i n S.M., Hes s K.L., G e a rhart J.M., G e is s K.T., S ch lage r J.J. In vitro toxicity of nanoparticles in BRL 3A rat liver cells. Toxicol. in Vitro, 2005, 19(7): 975-983 (doi: 10.1016/j.tiv.2005.06.034).

25. Akhtar M.J., Ahamed M., Alhadlaq H.A., Alshamsan A., Khan M.A., Alrokayan S.A. Antioxidative and cytoprotective response elicited by molybdenum nanoparticles in human cells. J. Colloid Interf. Sci., 2015, 457: 370-377 (doi: 10.1016/j.jcis.2015.07.034).

26. Zhou S., Zhang C., Xiao Q., Zhuang Y., Gu X., Yang F., Xing C., Hu G., $\mathrm{C}$ a o $\mathrm{H}$. Effects of different levels of molybdenum on rumen microbiota and trace elements changes in tissues from goats. Biol. Trace Elem. Res., 2016, 174(1): 1-8 (doi: 10.1007/s12011-016-0706-3).

27. B o u rke C.A. Molybdenum deficiency produces motor nervous effects that are consistent with amyotrophic lateral sclerosis. Front. Neurol., 2016, 7: 28 (doi: 10.3389/fneur.2016.00028).

28. Huang X., Xie J., Cui X., Zhou Y., Wu X., Lu W., Shen Y., Yuan J., Chen W. Association between concentrations of metals in urine and adult asthma: a case-control study in Wuhan, China. PLoS ONE, 2016, 11(5): e0155818 (doi: 10.1371/journal.pone.0155818).

29. Chan P.C., Herbert R.A., Roy croft J.H., H a s e man J.K., Grumbein S.L., $\mathrm{M}$ i $11 \mathrm{e} \mathrm{r}$ R.Al. Lung tumor induction by inhalation exposure to molybdenum trioxide in rats and mice. Toxicol. Sci., 1998, 45(1): 58-65. 